\title{
RF Performance of Layer-Structured Broadband Passive Millimeter-Wave Imaging System
}

\author{
Kunio Sakakibara, ${ }^{1}$ Kunihiko Ohkawa, ${ }^{2}$ Yutaka Aoki, ${ }^{2}$ and Nobuyoshi Kikuma ${ }^{1}$ \\ ${ }^{1}$ Nagoya Institute of Technology, Nagoya 466-8555, Japan \\ ${ }^{2}$ DENSO CORPORATION, Kariya 448-8661, Japan \\ Correspondence should be addressed to Kunio Sakakibara; sakaki@nitech.ac.jp
}

Received 4 October 2015; Revised 22 December 2015; Accepted 29 December 2015

Academic Editor: Wen-Qin Wang

Copyright (C) 2016 Kunio Sakakibara et al. This is an open access article distributed under the Creative Commons Attribution License, which permits unrestricted use, distribution, and reproduction in any medium, provided the original work is properly cited.

Low profile and simple configuration are advantageous for RF module in passive millimeter-wave imaging system. High sensitivity over broad operation bandwidth is also necessary to detect right information from weak signal. We propose a broadband layerstructured module with low profile, simple structure, and ease of manufacture. This module is composed of a lens antenna and a detector module that consists of a detector circuit and a broadband microstrip-to-waveguide transition. The module forms a layer structure as a printed substrate with detector circuit is fixed between two metal plates with horn antennas and back-short waveguides. We developed a broadband passive millimeter-wave imaging module composed of a lens antenna and a detector module in this work. The gain and the antenna efficiency were measured, and the broadband operation was observed for the lens antenna. For the detector module, peak sensitivity was $8100 \mathrm{~V} / \mathrm{W}$. Furthermore, the detector module recognized a difference in the absorber's temperature. The designs of the lens antenna and the detector module are presented and the RF performances of these components are reported. Finally, passive millimeter-wave imaging of a car, a human, and a metal plate in clothes is demonstrated in this paper.

\section{Introduction}

Millimeter-waves penetrate various materials, including fabric, fire, and fog [1-13]. Millimeter-wave imaging can be applied to detection of concealed weapons and of fire victims and in monitoring car surroundings. There are two types of millimeter-wave imaging systems: passive- and activeimaging systems. As active-imaging systems radiate millimeter-waves over the coverage area and receive reflected waves from objects, high $S / N$ ratio can be expected. However, a part of the object, whose tangential plane is orthogonal to the line connecting the target and the radar, reflects the wave back to the radar. Therefore, only that part can be detected by the active-imaging systems. On the other hand, a passive-imaging system does not have a transmitter; then, heat emission from all the parts of the objects transmits to the receiver. Consequently, only the limited part can be detected by the active-imaging systems, while the profile of the object can be detected by the passive-imaging systems.
The phenomenon in active imaging is called by "speckle" or "glint" [14]. However, because heat emission from objects is quite weak, passive-imaging systems are disadvantageous at the point of low $S / N$ ratio compared to active-imaging systems. Therefore, low power-loss, high sensitivity, and broadband operation are required for passive-imaging modules [1, 4]. Some detector modules with sensitivity higher than $550 \mathrm{~V} /$ $\mathrm{W}$ in millimeter-wave band have been produced [15]. Then, a high-performance passive-imaging module also has been developed in some organizations [5, 11]. In this module, a detector circuit is integrated on the same alumina substrate with Fermi antenna. High sensitivity with $150 \mathrm{~V} / \mathrm{W}$ and broadband operation are successfully achieved. However, a number of substrates are vertically arranged with specific spacing for the two-dimensional arrangement of the detectors with antennas.

The purpose of this research is to develop a passiveimaging module with a layer structure, which is advantageous at the points of low profile and ease of manufacture. We have 


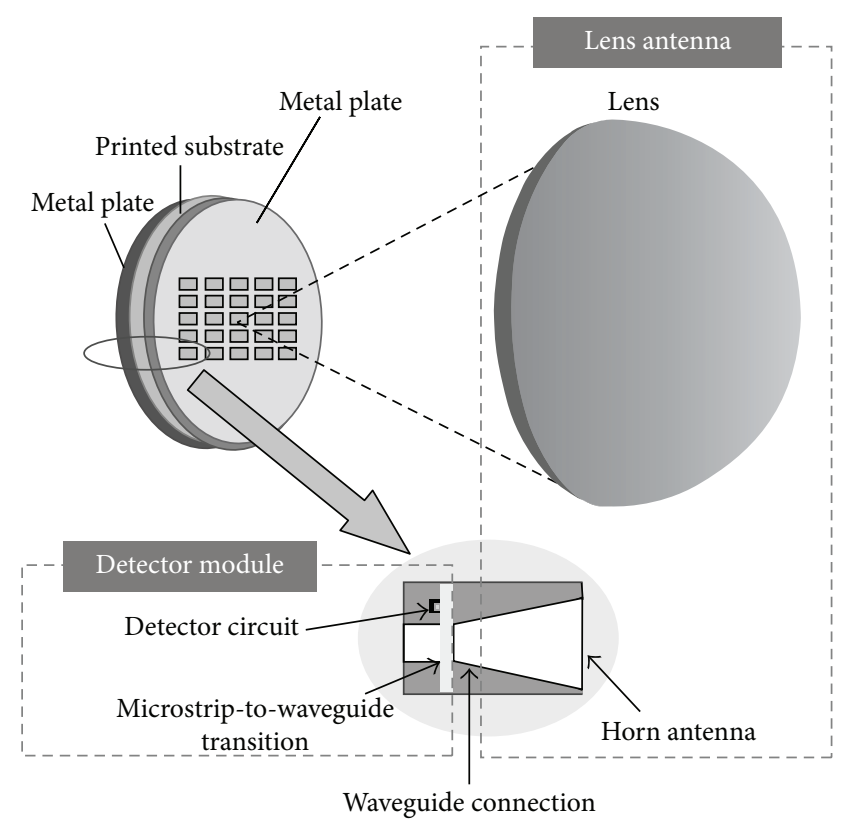

FIGURE 1: Configuration of layer-structured module for passive millimeter-wave imaging.

already proposed the configuration of the detector module and reported some results of the first-fabricated detector circuit [16-18]. The detail design for optimization and RF evaluation of a lens antenna and a detector module for imaging are reported in this paper. We designed a single detector module as the first step in this work. In Section 2, we indicate configuration of the proposed module, composed of a lens antenna and a detector module. Section 3 describes the design and performance of a lens antenna. Section 4 presents the design and performance of a detector module with imaging demonstrations, and Section 5 concludes.

\section{Configuration of Layer-Structured Module for Passive Millimeter-Wave Imaging}

The configuration of the proposed layer-structured imaging module is shown in Figure 1. This module is composed of a lens antenna and a detector module. A lens antenna is composed of lens and horn antennas arranged around the focal point of the lens. Both the lens and the horn antennas are advantageous at the point of broadband operation. The horn antennas are composed of tapered holes and are arranged easily by making holes on the metal plate. Each horn antenna is connected to a detector module. The detector module is composed of a detector circuit and a microstripto-waveguide (MS-WG) transition to connect the planar detector circuit to the waveguide horn antenna.

Since a printed substrate with detector circuit is fixed between two metal plates, the imaging module forms layer structure, as shown in Figure 2. The top layer includes a pyramidal horn antenna. Thickness of this layer is about $15 \mathrm{~mm}$, which corresponds to the horn length. The middle layer is an alumina substrate and consists of a detector circuit

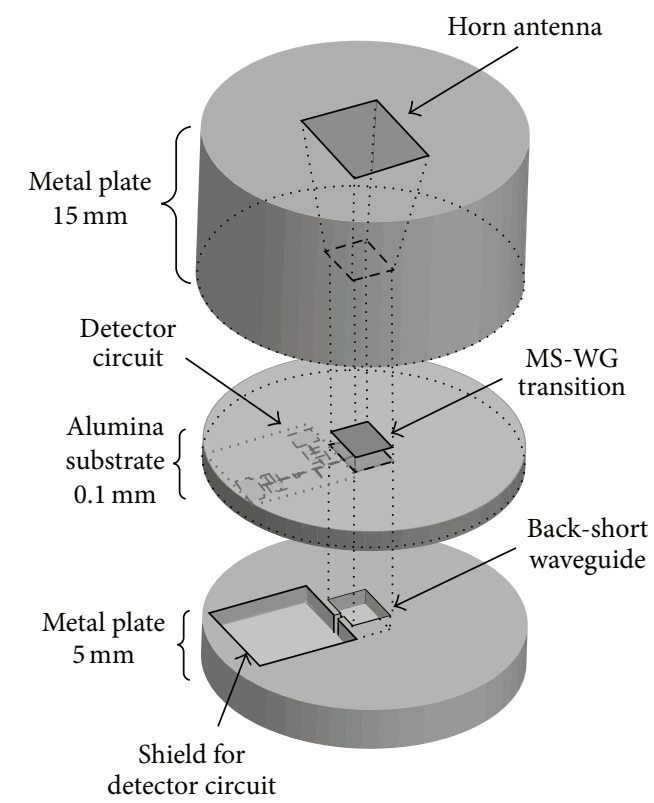

Figure 2: Configuration of the layer-structured detector module with a horn antenna. It is composed of a horn antenna, an MS-WG transition, and a detector circuit.

and an MS-WG transition to connect the waveguide horn antenna and the detector circuit printed on the back of the substrate. This layer is about $0.1 \mathrm{~mm}$ thick. The bottom layer consists of back-short waveguide for the MS-WG transition and a shield for the detector circuit. This layer is less than $5 \mathrm{~mm}$ thick. The total thickness of this layer structure is only about $20 \mathrm{~mm}$.

\section{Lens Antenna}

A lens antenna is composed of a microwave lens and a horn antenna. The lens is designed to focus all the incident waves on one focal point, and the horn antenna is designed to receive all focused waves efficiently. In this section, we describe the design of a lens and a horn antenna and then discuss the overall performance of the lens antenna.

3.1. Design of Lens. The gain and the beamwidth of lens depend on the size of the aperture. The gain $G$ is related to the effective aperture area $A_{e}$ of the lens diameter $D$ by

$$
G=\frac{4 \pi A_{e}}{\lambda^{2}},
$$

where $\lambda$ is a wavelength of free space. Here, diameter $D$ is determined as $200 \mathrm{~mm}$ for machining condition. Therefore, the gain is roughly expected to be $40 \mathrm{dBi}$ with $50 \%$ efficiency. To efficiently receive incident wave through lens by horn antenna, transformation coefficients are employed in the design $[5,19]$. The transformation coefficient $\alpha$ between the lens and horn antenna is defined by

$$
\alpha=\frac{\left|\int_{-\pi / 2}^{\pi / 2} p(\theta) q(\theta) d \theta\right|^{2}}{\left.\left|\int_{-\pi / 2}^{\pi / 2}\right| p(\theta)\right|^{2} d \theta|| \int_{-\pi / 2}^{\pi / 2}|q(\theta)|^{2} d \theta \mid},
$$




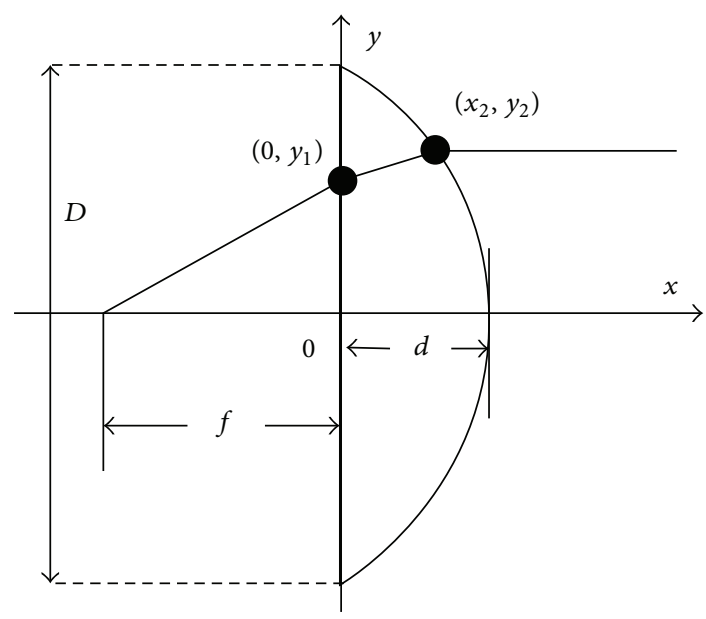

FIGURE 3: Coordinate system in the design of lens contour.

where $p(\theta)$ is the radiation pattern of the horn antenna and $q(\theta)$ is the lens beam pattern. If the incident wave over the lens is received perfectly by the antenna, $\alpha$ is unity. The transformation coefficient is maximum $(\alpha=0.79)$ when the effective beamwidth is 52 degrees. Therefore, focal length $f$ is identical to $D / 2 \tan 26^{\circ}$. The lens contour is designed using the coordinate system shown in Figure 3 to focus in phase all the incident plane waves on one focal point. The coordinates of the lens contour correspond to $\left(x_{2}, y_{2}\right)$ and are obtained from the following equations:

$$
\begin{aligned}
\frac{y_{1}}{\sqrt{f^{2}+y_{1}^{2}}}= & \frac{y_{2}-y_{1}}{\sqrt{\left(y_{2}-y_{1}\right)^{2}+x_{2}^{2}}} \\
f+n d= & \sqrt{f^{2}+y_{1}^{2}}+n \sqrt{x_{2}^{2}+\left(y_{2}-y_{1}\right)^{2}} \\
& +\left(d-x_{2}\right),
\end{aligned}
$$

where $n$ is refractive index. Equation (3) represents Snell's law on the boundary of $y z$-plane. Equation (4) imposes equal electric path-length on all the incident waves. The design parameters of the lens are shown below:

(i) Diameter $D$ of lens: $200 \mathrm{~mm}$.

(ii) Focal length $f: 205 \mathrm{~mm}$.

(iii) Thickness $d$ of lens: $60 \mathrm{~mm}$.

(iv) Material of lens: polyethylene.

(v) Refractive index $n$ of polyethylene: 1.516.

3.2. Design of Horn Antenna. A horn antenna is used to receive power from objects through the lens. To obtain high transformation efficiency, $10 \mathrm{~dB}$ beamwidth of horn antenna is designed to be at 52 degrees. As a result of optimization by electromagnetic analysis [20], the aperture size of horn antenna is $9.4 \mathrm{~mm} \times 6.6 \mathrm{~mm}(H$-plane $\times E$-plane $)$ and the horn length is $15 \mathrm{~mm}$, which is the minimum value for symmetrical $10 \mathrm{~dB}$ beamwidth in $E$ - and $H$-planes between 60 to $90 \mathrm{GHz}$.

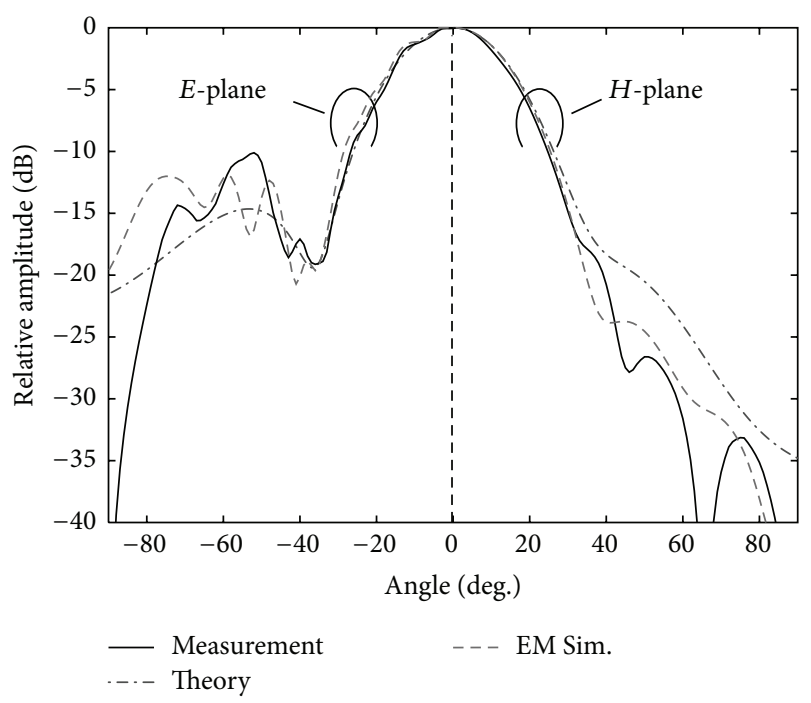

FIGURE 4: Radiation patterns of horn antenna (76.5 GHz).

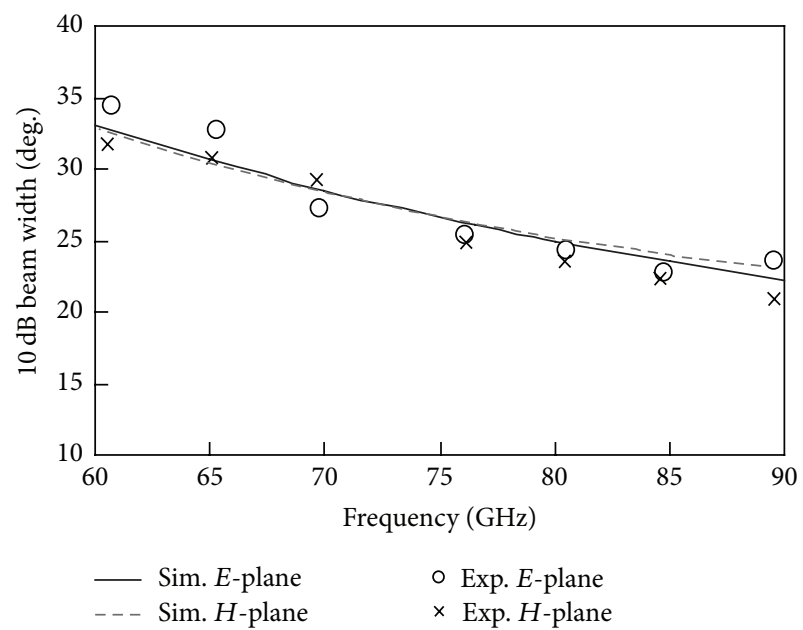

Figure 5: Frequency dependency of $10 \mathrm{~dB}$ beamwidth.

We fabricated the designed horn antenna. Directivity in measurement, theory, and electromagnetic simulation is shown in Figure 4. Measured $10 \mathrm{~dB}$ beamwidth of both the $E$ and $H$-planes is approximately 52 degrees. The sidelobe of $E$ plane is $-10.3 \mathrm{~dB}$, which is higher than that of $H$-plane due to the effect of the ground plane. Figure 5 shows the frequency dependency of the $10 \mathrm{~dB}$ beamwidth. The $10 \mathrm{~dB}$ beamwidth of $E$ - and $H$-planes agrees well over 60 to $90 \mathrm{GHz}$ both in the simulation and in the experiment.

3.3. Performance of Lens Antenna. The fabricated lens antenna composed of the lens and the horn antenna is evaluated by near-field measurement as shown in Figure 6. The directive radiation pattern is obtained by applying discrete Fourier transform to near-field measurement data. Figure 7 shows the measured $E$-plane radiation pattern of lens antenna. The $3 \mathrm{~dB}$ beamwidth is 1.6 degrees in the broadside direction, whereas it is 1.3 degrees in the simulation. Figure 8 shows 


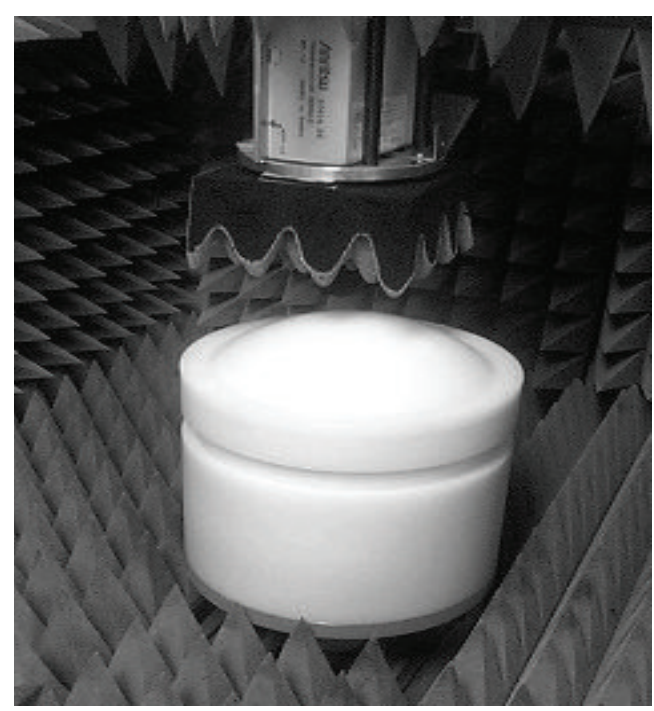

Figure 6: Near-field measurement of lens antenna.

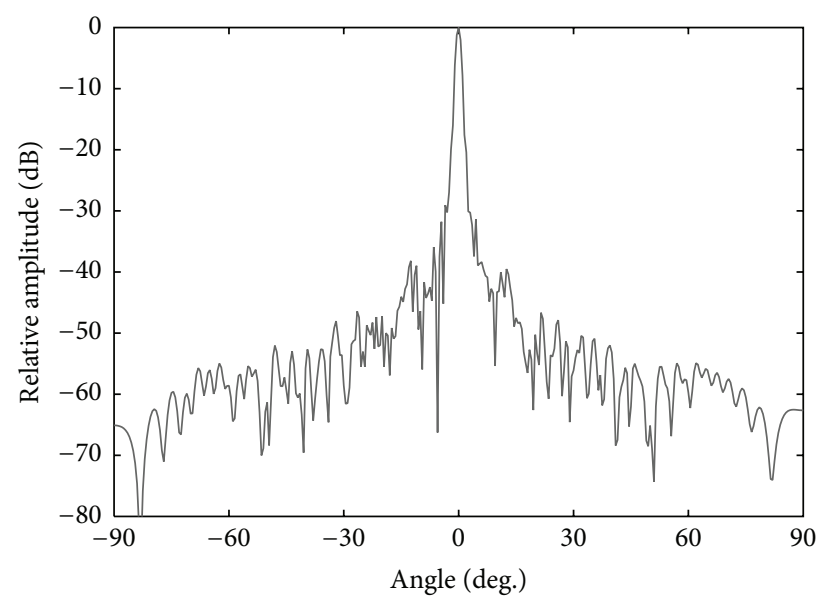

Figure 7: Measured radiation pattern of lens antenna (76.5 GHz).

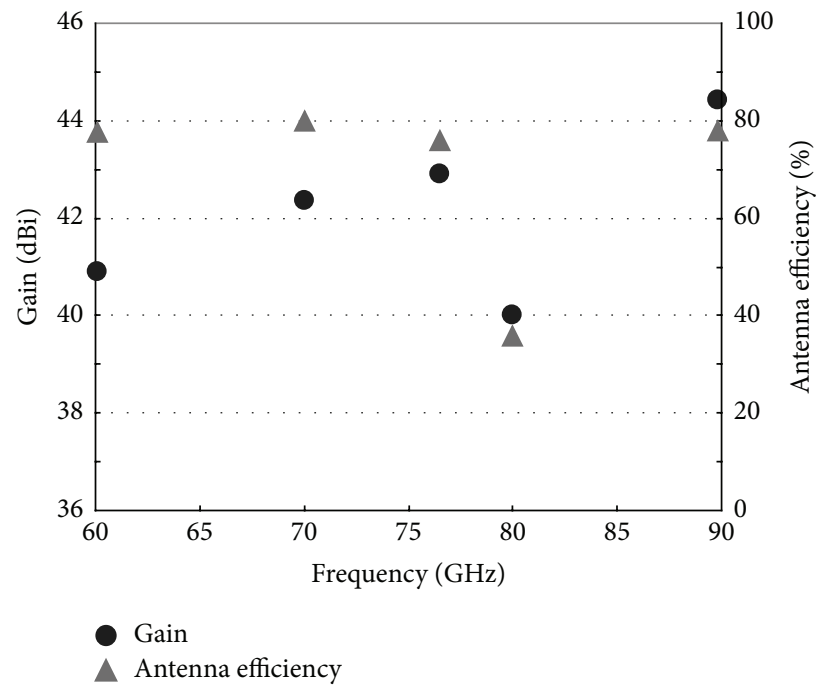

Figure 8: Measured gain and antenna efficiency of lens antenna.

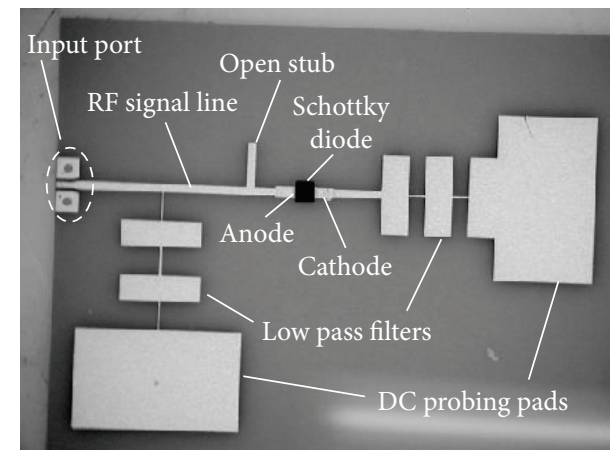

Figure 9: Photograph of detector circuit.

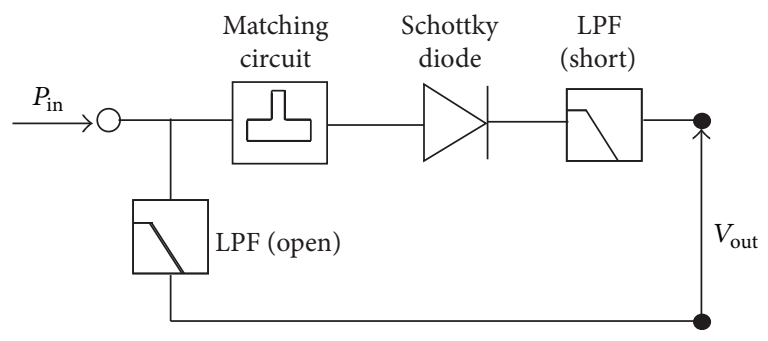

FIGURE 10: Block diagram of detector circuit.

the measured gain and the antenna efficiency over 60 to $90 \mathrm{GHz}$. The gain was $43 \mathrm{dBi}$ and the antenna efficiency was $75.3 \%$ at $76.5 \mathrm{GHz}$. The gain was higher than $40 \mathrm{dBi}$ over 60 to $90 \mathrm{GHz}$. Antenna efficiency was over $70 \%$, except at $80 \mathrm{GHz}$. The cause of efficiency degradation at $80 \mathrm{GHz}$ is still under investigation. A future study will focus on improving frequency dependency.

\section{Detector Module}

A detector module is composed of a detector circuit and an MS-WG transition to connect the planar detector circuit to the waveguide-fed horn antenna of the lens antenna. In this section, we first describe the design of the detector circuit and the MS-WG transition. Next, we discuss the total performance of the detector module.

\subsection{Design of Detector Circuit}

4.1.1. Circuit Configuration. We designed a detector circuit on a printed substrate that operates in the millimeter-wave band. We evaluated the detector circuit by sensitivity, which is a ratio of output voltage divided by input power. Sensitivity is expected to be higher than $1000 \mathrm{~V} / \mathrm{W}$ which is an average level of commercial detectors in this frequency range. A photograph and a block diagram of the developed detector circuit are shown in Figures 9 and 10, respectively. Alumina substrate (thickness: $0.1 \mathrm{~mm}$; relative dielectric constant $\varepsilon_{r}$ : 10.0 ) is used. A diode is placed at the open terminal of the $\mathrm{RF}$ signal line. Input RF signal is rectified by a diode, and DC 


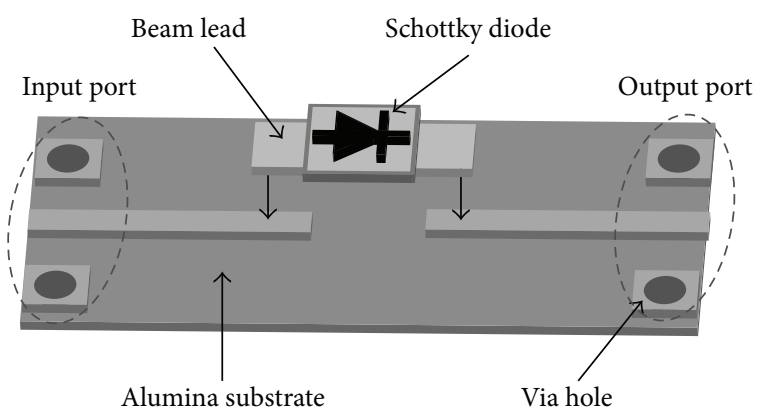

FIGURE 11: Measurement setup for $S$-parameters of series connected diode.

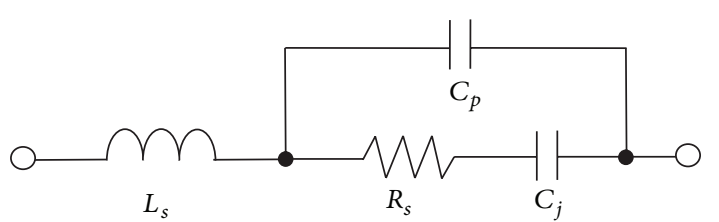

FIgURE 12: Equivalent circuit of the diode.

voltage between both diode terminals is detected as output voltage. DC probing pads are placed via low pass filter (LPF) to isolate the effect from the RF characteristic. The LPF with short input impedance is placed at the cathode terminal, while the LPF with open input impedance is placed at the anode terminal. Furthermore, a matching circuit is placed at the anode terminal of the diode to transmit the input RF signal to the diode efficiently. As the detector circuit is fed by a coplanar probe, the input port forms a coplanar-tomicrostrip transition. Consequently, there are three items in the design procedure for the detector circuit:

(i) Extracting equivalent circuit of diode.

(ii) Design of matching circuit.

(iii) Design of LPF.

Their details are described in the following sections.

4.1.2. Extracting Equivalent Circuit of Diode. A Schottky barrier diode HSCH9161 of Avago Technologies is used in the detector circuit [21]. Since HSCH9161 is a zero-bias diode, a bias circuit is unnecessary. To extract the equivalent circuit of the diode on the circuit simulator, the $S$-parameters of the diode are measured by vector network analyzer in the setup shown in Figure 11. The diode is mounted on a gap of the microstrip line on the alumina substrate and connected via beam leads. With the microstrip line fed by coplanar probes, the input and output ports form coplanar-to-microstrip transitions. Figure 12 shows the equivalent circuit of the diode used in the simulation. $L_{s}, R_{s}, C_{j}$, and $C_{p}$ are optimized to fit the simulated $S$-parameters with the measured ones. As a result of the extraction, when $L_{s}, R_{s}, C_{j}$, and $C_{p}$ are $0.19 \mathrm{nH}, 50 \Omega, 6.7 \mathrm{fF}$, and $9.5 \mathrm{fF}$, respectively, the difference in $S_{11}$ between simulation and measurement is $0.03 \mathrm{~dB}$ in amplitude and 20 degrees in phase at $76.5 \mathrm{GHz}$. On the other hand, the difference in $S_{21}$ is $0.02 \mathrm{~dB}$ in amplitude and 1.0 degree in phase as given in Figure 13.

4.1.3. Design of Matching Circuit and Low Pass Filter. A matching circuit is designed to transmit the received power to the diode efficiently. We used an open stub for matching the circuit shown in Figure 9. The length of the open stub and the spacing between the diode and the open stub are optimized for the extracted diode parameters using a circuit simulator.

A microstrip-line LPF is composed of series connections of wide and narrow lines, as shown in Figure 9 [22]. As a wide line operates as shunt capacitance and a narrow line operates as series inductance, this circuit operates as an LPF. Therefore, the width and the length of the lines determine the characteristic of the LPF. Figure 14 shows electromagneticsimulated $S_{11}$ of LPFs with open and short input impedances. $S_{11}$ of LPFs are relatively stable in the frequency range over 60-80 GHz.

4.1.4. Performance of Detector Circuit. The detector circuit is fabricated on the alumina substrate. Figure 15 shows the measured sensitivity and the simulated and measured $S_{11}$ of the detector circuit. Bandwidth of reflection below $-10 \mathrm{~dB}$ is $1.9 \mathrm{GHz}$ in simulation and $1.4 \mathrm{GHz}$ in measurement. The bandwidth is not very wide due to characteristic of the matching circuit. There is a $4 \mathrm{GHz}$ difference between the measured and the simulated resonant frequencies. This difference could be due to the moderate accuracy in extraction of the equivalent circuit for the diode. Sensitivity is a ratio of output voltage divided by input power. In this case, the input power is $-30 \mathrm{dBm}$. As a result, the peak sensitivity is $8900 \mathrm{~V} / \mathrm{W}$ at $74 \mathrm{GHz}$. The bandwidth of sensitivity above $1000 \mathrm{~V} / \mathrm{W}$ is $10 \mathrm{GHz}$. The measured sensitivity is high in the frequency band with low reflection. Figure 16 shows the sensitivity versus the input power. Saturation of sensitivity is observed for input power below $-30 \mathrm{dBm}$. This result indicates that the developed detector circuit operates below $-30 \mathrm{dBm}$ to obtain linear output for input power.

4.2. Microstrip-to-Waveguide Transition. The waveguide-fed horn antenna and the planar detector circuit are connected by an MS-WG transition. Because the detector circuit resonates at $73 \mathrm{GHz}$ as shown in Figure 15, the design frequency of the MS-WG transition is fixed at $73 \mathrm{GHz}$. The structure of the MS-WG transition is shown in Figure 17. A printed substrate (fluorocarbon resin film, thickness $t=0.127 \mathrm{~mm}$, relative dielectric constant $\varepsilon_{r}=2.2$, and loss tangent $\tan \delta=0.001$ ) with conductor patterns on both planes is placed on an open-ended waveguide. The aperture of the printed substrate is covered with a back-short waveguide. The height of the back-short waveguide is approximately $\lambda_{g} / 4\left(\lambda_{g}\right.$ : guided wavelength of the waveguide) [23]. To reduce the leakage of parallel plate transmitting mode into the substrate, the waveguide in the substrate is surrounded by via holes. Furthermore, a microstrip line is inserted into the waveguide to couple with waveguide $\mathrm{TE}_{10}$ mode. Hence, the important design parameters are the height of the back-short waveguide 

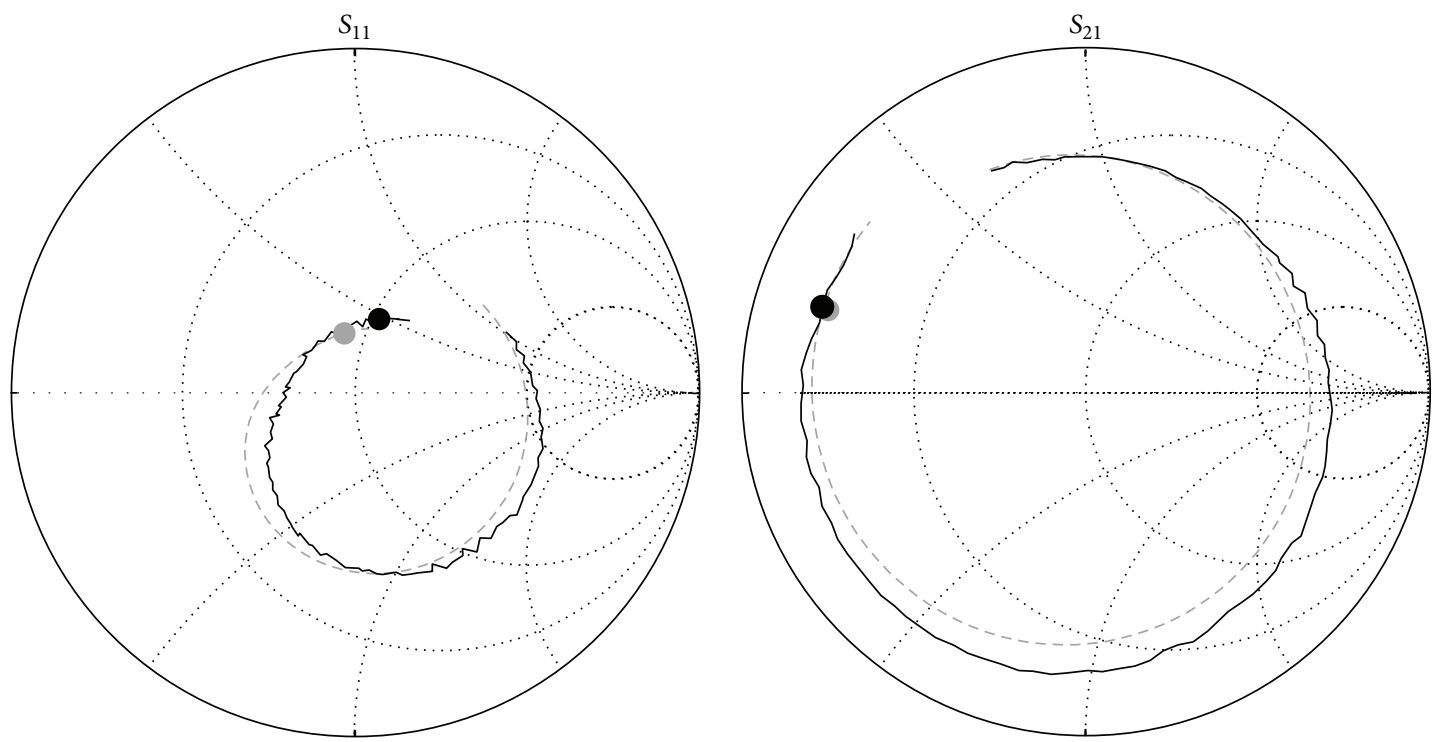

- - Simulation

- Measurement

Frequency: 67 77 GHz

$76.5 \mathrm{GHz}$
- - Simulation

— Measurement

Frequency: $67 \sim 77 \mathrm{GHz}$

$76.5 \mathrm{GHz}$

Figure 13: Measured S-parameters of the series-connected diode.
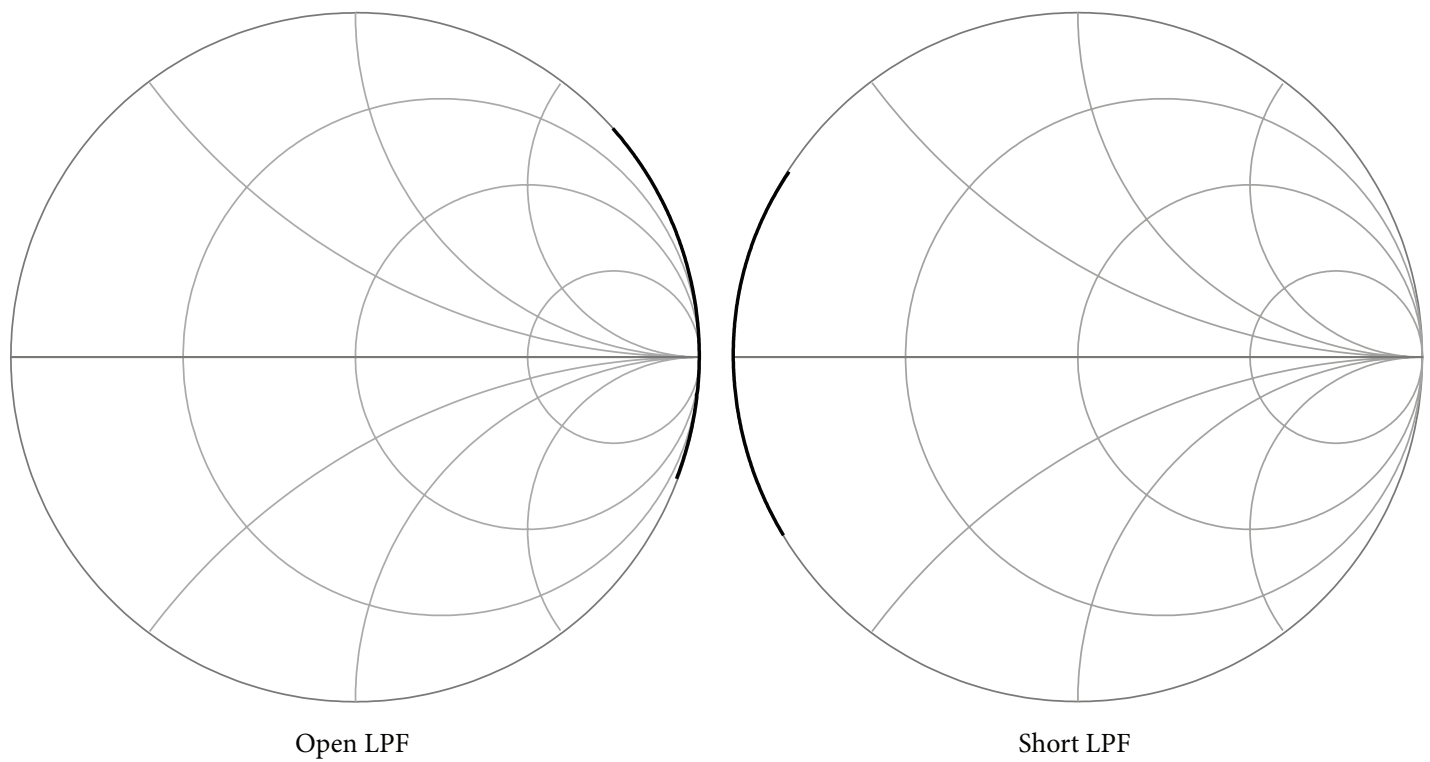

FIGURE 14: Simulated $S_{11}$ of LPFs (frequency: $60-80 \mathrm{GHz}$ ).

and the inserted length of the microstrip line. Figure 18 shows the simulated and the measured $S$-parameters of the fabricated MS-WG transition. Resonant frequency is $73 \mathrm{GHz}$. Bandwidth for reflection lower than $-20 \mathrm{~dB}$ is $4.8 \mathrm{GHz}$. $S_{21}$ at $73 \mathrm{GHz}$ is $-0.94 \mathrm{~dB}$ in measurement.

4.3. Performance of Detector Module. We fabricated a detector module composed of a lower feeding waveguide, a printed substrate, and an upper back-short waveguide, as is shown in Figure 19. The MS-WG transition and the detector circuit are connected by a microstrip line. In this section, we analyze the performance of the detector module. First, we measured the sensitivity of the detector module supplied CW signal from an oscillator. Next, a Dicke radiometer [24] is constructed by using the developed detector module. In this case, the input source is radiation from objects. To confirm 


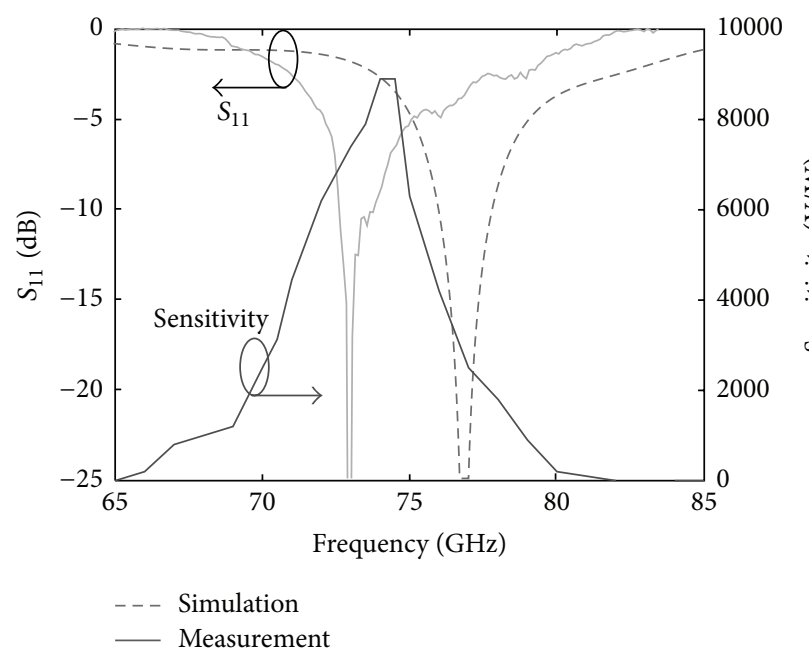

FIGURE 15: Measured sensitivity and simulated and measured $S_{11}$ of the detector circuit.

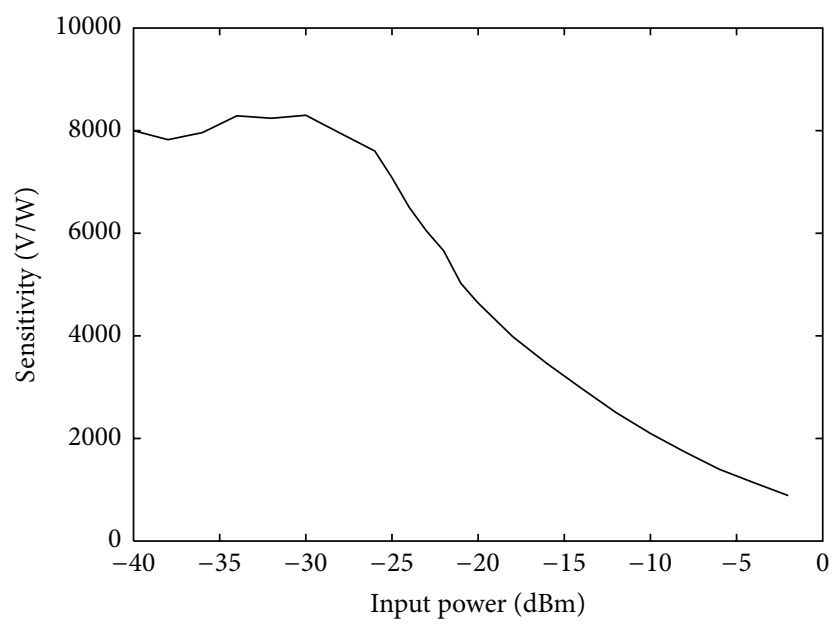

FIGURE 16: Sensitivity of the detector circuit versus input power.

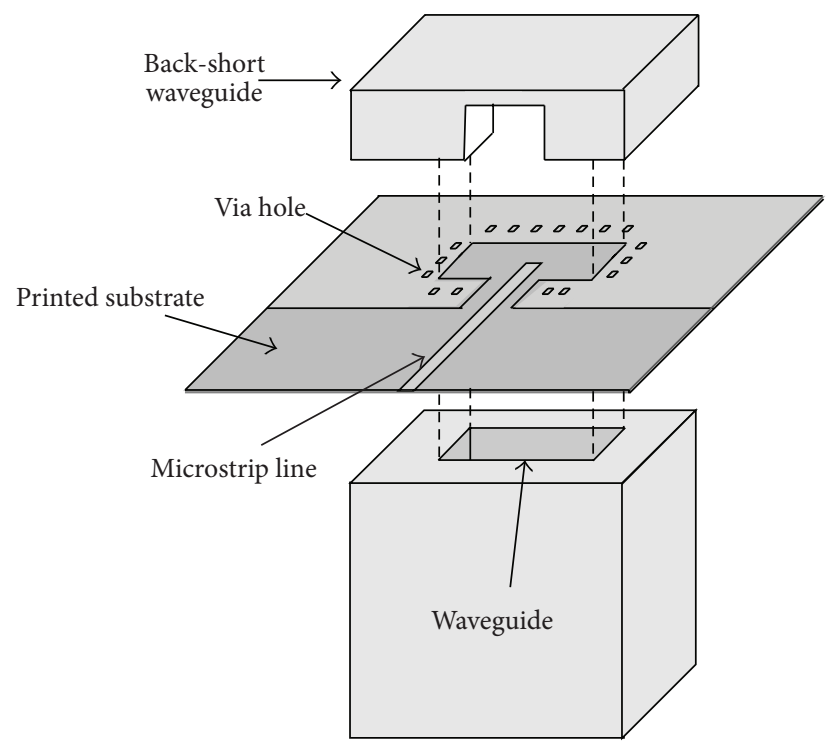

FIGURE 17: Structure of the MS-WG transition.

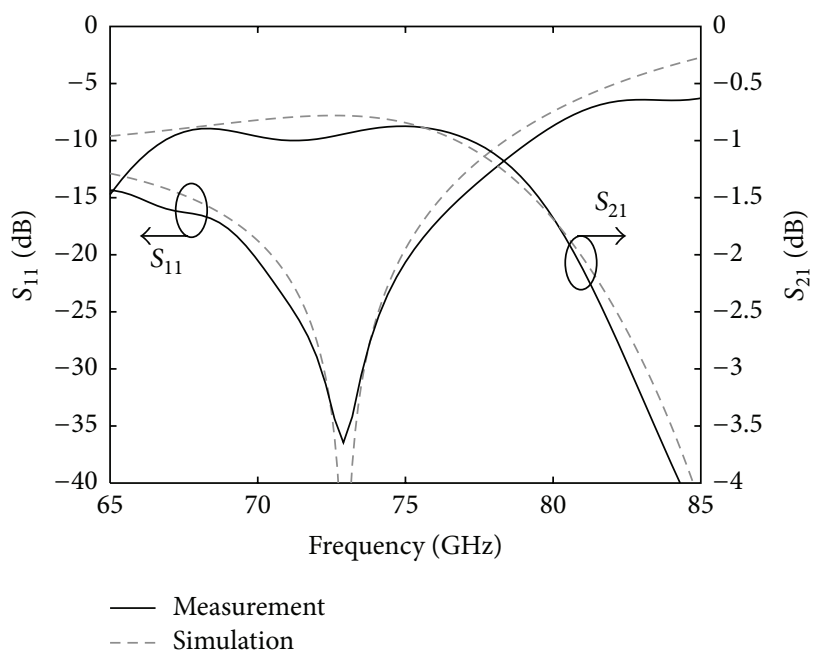

FIGURE 18: Simulated and measured $S$-parameters of the MS-WG transition.

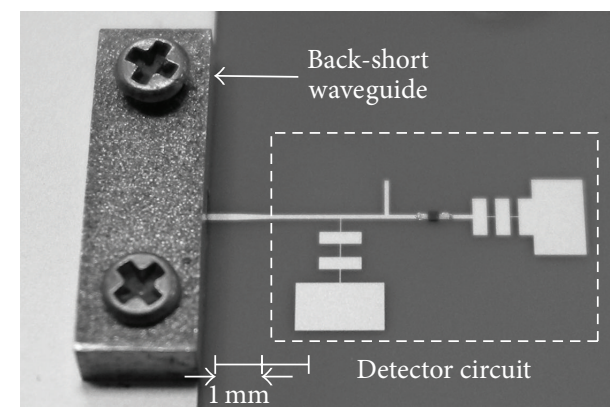

Figure 19: Photograph of the detector module.

the contrast of object temperature, the readout voltage versus the temperature of absorber on the antenna is measured. Furthermore, we compared readout voltage between the sky and the absorber.

4.3.1. Sensitivity Measurements. We measured $S_{11}$ and sensitivity of the detector module using a waveguide-input oscillator for input CW source. Input power is $-30 \mathrm{dBm}$. The measured frequency dependencies of $S_{11}$ and sensitivity are shown in Figure 20. The bandwidth of reflection below $-10 \mathrm{~dB}$ is $4.9 \mathrm{GHz}$. The peak sensitivity is $8100 \mathrm{~V} / \mathrm{W}$ at $73 \mathrm{GHz}$, and the bandwidth of sensitivity above $1000 \mathrm{~V} / \mathrm{W}$ is $10 \mathrm{GHz}$. Figure 21 shows the input power dependency of sensitivity. The sensitivity of the detector module saturates when the input power is below $-30 \mathrm{dBm}$. These results are quite reasonable and comparable with that of the detector circuit observed in Figures 15 and 16.

4.3.2. Receiving Experiments. We constructed the Dicke radiometer and evaluated its readout voltage when the module receives radiation from objects. The configuration of Dicke radiometer is shown in Figure 22. We observed a difference of the output voltage between the antenna port and the reference 


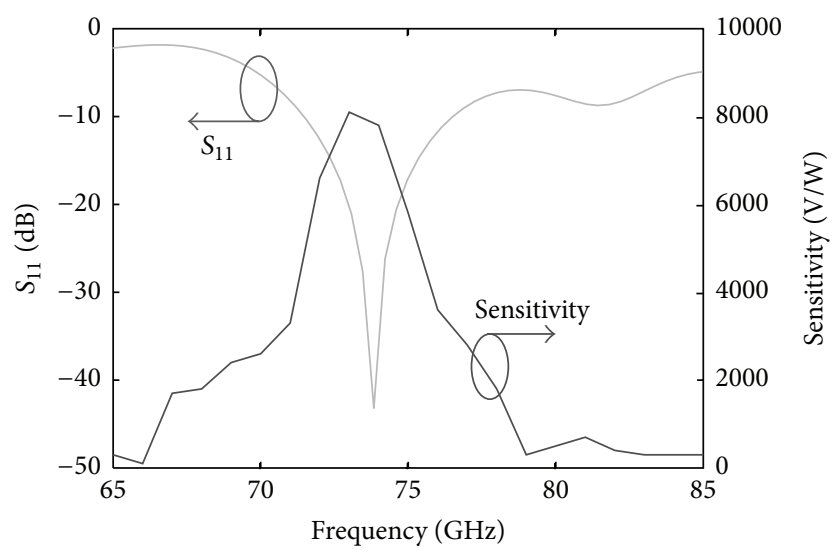

Figure 20: Measured $S_{11}$ and sensitivity of the detector module.

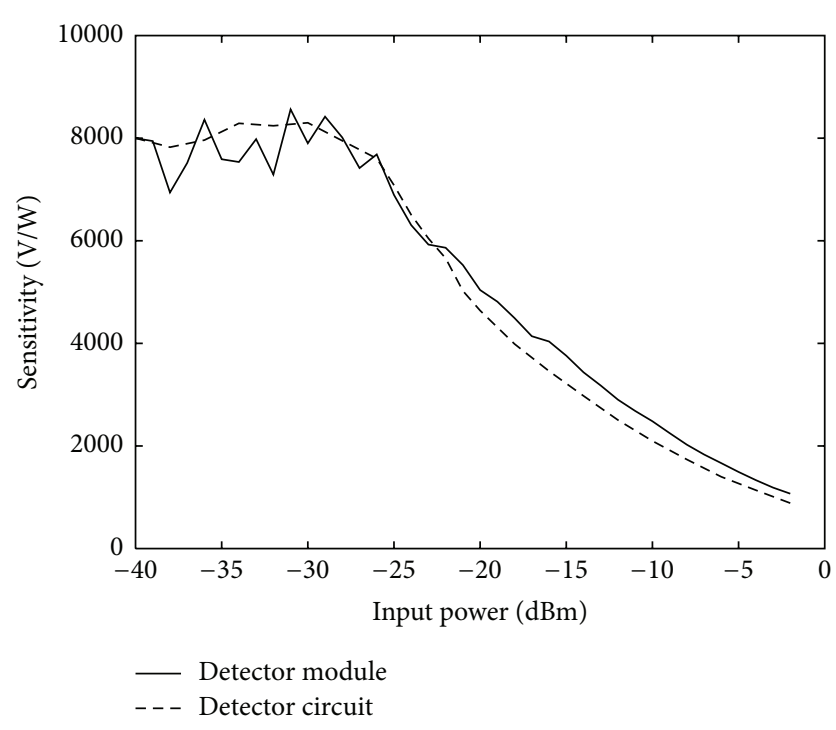

FIGURE 21: Input power dependency for sensitivity of detector module.

port. The readout voltage is obtained using a Dicke switch and a lock-in amplifier synchronized by a pulse generator. The specifications of the Dicke radiometer are shown below:

(i) Design frequency: $76.5 \mathrm{GHz}$.

(ii) RF amplifier gain: $50 \mathrm{~dB}$.

(iii) Bandwidth: $1 \mathrm{GHz}$.

(iv) Switching frequency: $100 \mathrm{kHz}$.

The readout voltage is measured when changing temperature of absorber, which is located on the horn antenna. Figure 23 shows the measured readout voltage for the temperature change of the absorber. It is confirmed from Figure 23 that the readout voltage is almost proportional to the temperature of the absorber. Furthermore, there is $60 \mu \mathrm{V}$ difference between $278 \mathrm{~K}$ and $298 \mathrm{~K}$. We measured the readout voltage when receiving radiations from sky and absorber with room temperature. Table 1 shows measured results. The difference
TABLE 1: Comparison of readout voltages between sky and absorber.

\begin{tabular}{lc}
\hline Source & Readout voltage $(\mu \mathrm{V})$ \\
\hline Absorber in room temperature $(300 \mathrm{~K})$ & 33.7 \\
Sky & 59.3
\end{tabular}

in the readout voltages is $25.6 \mu \mathrm{V}$, which corresponds to the contrast between the sky and the absorber.

4.3.3. Imaging Demonstrations. Imaging experiments are implemented by using the developed module. One pixel is obtained by one shot. Therefore, two-dimensional view can be obtained by two-dimensional scanning. The range of the target from the imaging module is $3 \mathrm{~m}$. The angular resolution is derived as approximately $2 \mathrm{deg}$. from $\tan ^{-1}(1.22 \lambda / d)$, where $\lambda$ is a wavelength of free space and $d$ is a diameter of the antenna aperture [25]. Figure 24 shows the millimeterwave image of the car with the optical image. 61 pixels from -15 to +15 deg. in horizontal plane and 33 pixels from -8 to $+8 \mathrm{deg}$. in vertical plane are measured with $0.5 \mathrm{deg}$. pitch. The car profile and the border between the sky and the ground are recognized by the millimeter-wave imaging. Figure 25 shows the millimeter-wave image with the optical image of the human. An aluminum plate with $0.2 \mathrm{~m}$ square is in his cloth. 25 pixels from -6 to $+6 \mathrm{deg}$. in horizontal plane and 41 pixels from -10 to +10 deg. in vertical plane are measured with $0.5 \mathrm{deg}$. pitch. Profile of the human body, arms, and legs is obtained by millimeter-wave imaging. The aluminum plate in the cloth is not recognized by optical imaging but is possible by millimeter-wave imaging because millimeterwave can penetrate the clothes.

\section{Conclusion}

A layer-structured module for passive millimeter-wave imaging has been proposed in this paper. We designed and evaluated the lens antenna and the detector module. The results show that the gain of the lens antenna is over $40 \mathrm{dBi}$ from 60 to $90 \mathrm{GHz}$. Furthermore, antenna efficiency is about $80 \%$ from 60 to $90 \mathrm{GHz}$ except $80 \mathrm{GHz}$. We would investigate the improvement of frequency dependency in the future study. Regarding the detector module, the peak sensitivity is $8100 \mathrm{~V} / \mathrm{W}$ at $73 \mathrm{GHz}$, and the bandwidth over $1000 \mathrm{~V} / \mathrm{W}$ is $11 \mathrm{GHz}$. In the receiving demonstration, we have confirmed that the readout voltage is proportional to the temperature of the absorber. This shows that the developed detector module can detect the difference of absorber's temperature, which is proportional to the radiation power. Car, human profiles, and aluminum plate in cloth are recognized by the millimeterwave imaging experiments.

\section{Conflict of Interests}

The authors declare that there is no conflict of interests regarding the publication of this paper. 


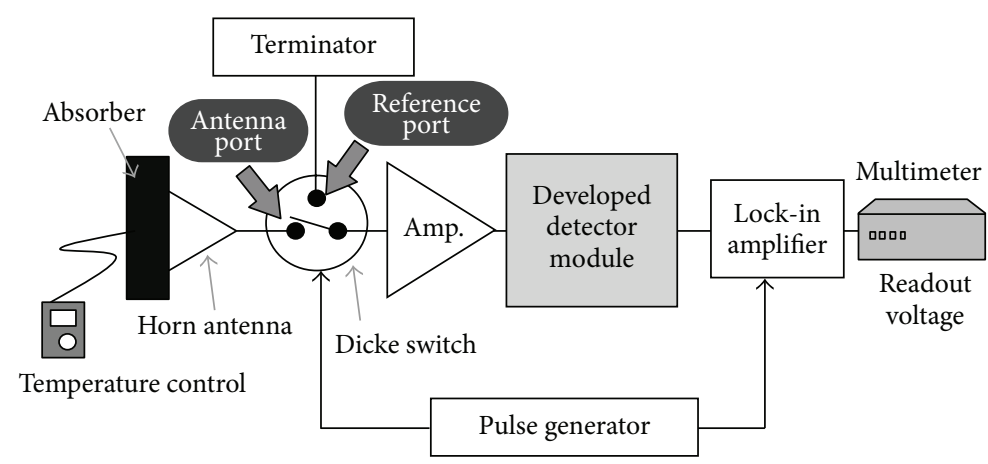

FIGURE 22: Configuration of Dicke radiometer.

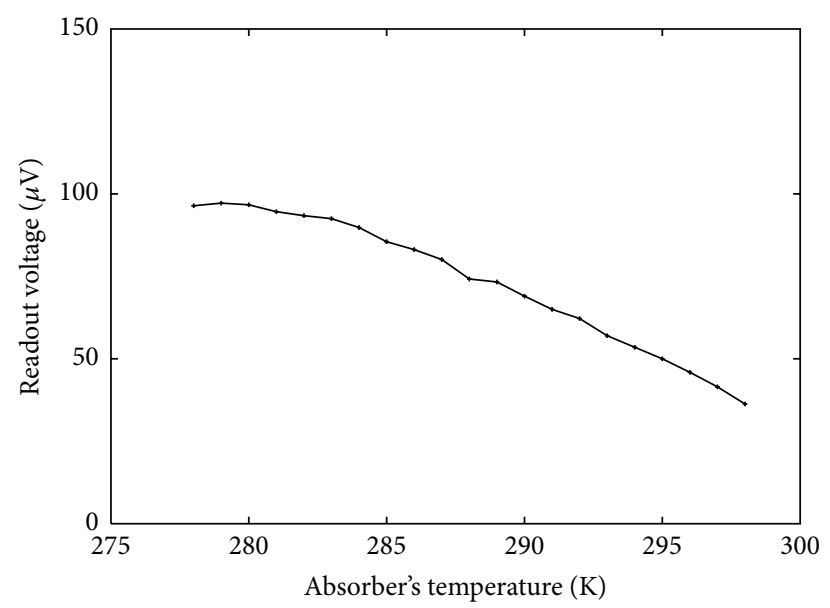

FIGURE 23: Measured readout voltage in changing temperature of absorber.

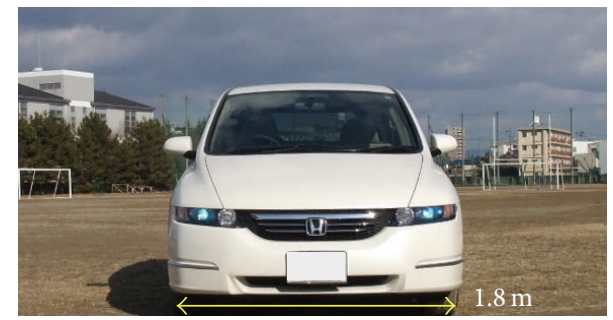

(a)

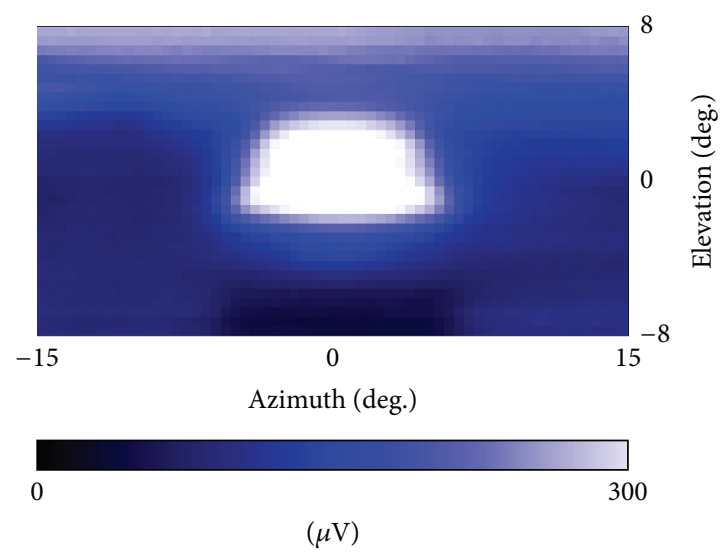

(b)

FIGURE 24: Experimental result of car imaging (a: optical; b: millimeter-wave). 


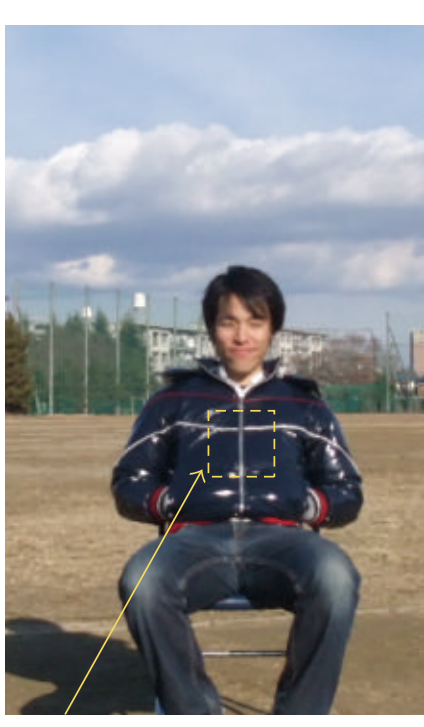

Metal plate $(0.2 \mathrm{~m} \times 0.2 \mathrm{~m})$

(a)
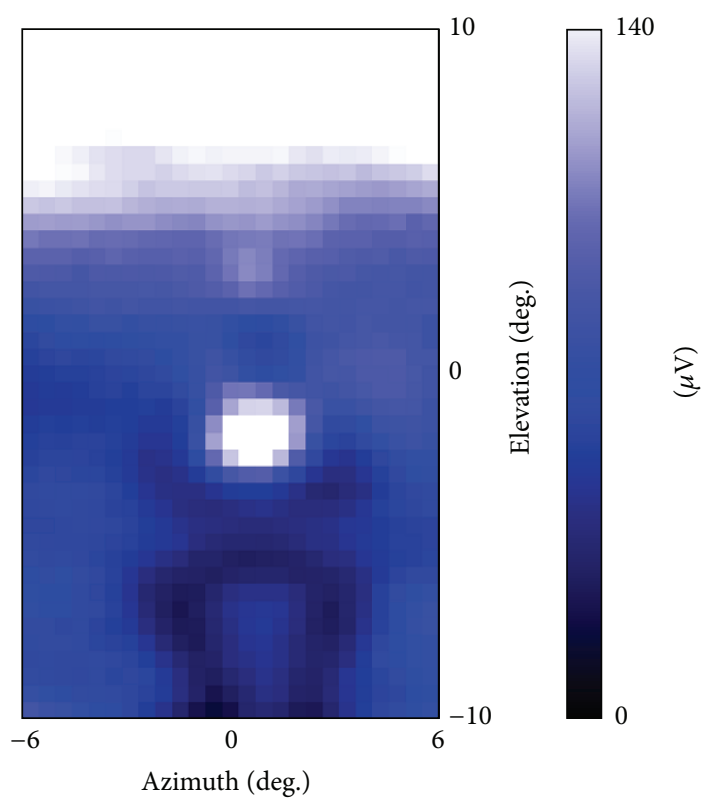

(b)

FIGURE 25: Experimental result of human imaging with metal plate in clothes (a: optical; b: millimeter-wave).

\section{Acknowledgments}

The authors are indebted to Mr. Masashi Ikeda, Mr. Takahiro Suzuki, and Mr. Wataru Maeda for the valuable contributions during their master course to complete this work.

\section{References}

[1] M. E. Tiuri, "Radio astronomy receivers," IEEE Transactions on Antennas and Propagation, vol. 12, no. 7, pp. 930-938, 1964.

[2] P. F. Goldsmith, C.-T. Hsieh, G. R. Huguenin, and J. Kapitzky, "Focal plane imaging systems for millimeter wavelengths," IEEE Transactions on Microwave Theory and Techniques, vol. 41, no. 10, pp. 1664-1675, 1993.

[3] G. R. Huguenin, E. L. Moore, S. Bandla, and J. J. Nicholson, "A millimeter-wave monolithic load switching twist reflector for compact imaging cameras," IEEE Transactions on Microwave Theory and Techniques, vol. 44, no. 12, pp. 2751-2757, 1996.

[4] K. Mizuno, K. Watanabe, J. Bae, T. Nozokido, and S. Sugawara, "Millimeter wave imaging technologies," in Proceedings of the Topical Symposium on Millimeter Waves, Hayama, Japan, July 1997.

[5] M. Joung, Y. Suzuki, K. Kanari et al., "A design of antenna for passive millimeter-wave imaging arrays," in Proceedings of the Asia-Pacific Microwave Conference (APMC '02), pp. 253-256, Kyoto, Japan, November 2002.

[6] L. Yujiri, M. Shoucri, and P. Moffa, "Passive millimeter wave imaging," IEEE Microwave Magazine, vol. 4, no. 3, pp. 39-50, 2003.

[7] R. Appleby, R. N. Anderton, S. Price et al., "Mechanically scanned real-time passive millimeter-wave imaging at $94 \mathrm{GHz}$," in Passive Millimeter-Wave Imaging Technology VI and Radar Sensor Technology VII, vol. 5077 of Proceedings of SPIE, pp. 16, Orlando, Fla, USA, April 2003.
[8] S. E. Clark, J. A. Lovberg, C. A. Martin, and V. G. Kolinko, "Passive millimeter-wave imaging for airborne and security applications," in Passive Millimeter-Wave Imaging Technology VI and Radar Sensor Technology VII, vol. 5077 of Proceedings of SPIE, pp. 16-21, Orlando, Fla, USA, August 2003.

[9] J. E. Bjarnason, T. L. J. Chan, A. W. M. Lee, M. A. Cells, and E. R. Brown, "Millimeter-wave, terahertz, and mid-infrared transmission through common clothing," Applied Physics Letters, vol. 85, no. 4, pp. 519-521, 2004.

[10] T. Lüthi and C. Mätzler, "Stereoscopic passive millimeter-wave imaging and ranging," IEEE Transactions on Microwave Theory and Techniques, vol. 53, no. 8, pp. 2594-2599, 2005.

[11] J. J. Lynch, H. P. Moyer, J. H. Schaffner et al., "Passive millimeterwave imaging module with preamplified zero-bias detection," IEEE Transactions on Microwave Theory and Techniques, vol. 56, no. 7, pp. 1592-1600, 2008.

[12] Y. Li, J. W. Archer, J. Tello et al., "Performance evaluation of a passive millimeter-wave imager," IEEE Transactions on Microwave Theory and Techniques, vol. 57, no. 10, pp. 2391-2405, 2009.

[13] J. W. May and G. M. Rebeiz, "Design and characterization of Wband SiGe RFICs for passive millimeter-wave imaging," IEEE Transactions on Microwave Theory and Techniques, vol. 58, no. 5, pp. 1420-1430, 2010.

[14] M. Sato and K. Mizuno, "Millimeter-wave imaging sensor," in Microwave and Millimeter Wave Technologies from Photonic Bandgap Devices to Antenna and Applications, I. Minin, Ed., InTech, 2010.

[15] Farran Technology, Detectors Datasheets, WDP-12, http://www .farran.com/shop/wdp/.

[16] K. Ohkawa, K. Sakakibara, Y. Aoki, N. Kikuma, and H. Hirayama, "Design of detector circuit for layer structured imaging module," in Proceedings of the Asia-Pacific Microwave Conference (APMC '06), FR4C-3, Yokohama, Japan, December 2006.

[17] T. Suzuki, K. Ohkawa, M. Ikeda et al., "Design of lens antenna and detector circuit for layer structured imaging module," in 
Proceedings of the International Symposium on Antennas and Propagation (ISAP '07), POS 2-4, pp. 1114-1117, Niigata, Japan, August 2007.

[18] M. Ikeda, T. Suzuki, K. Ohkawa et al., "RF performance of layerstructured passive millimeter-wave imaging module," in Proceedings of the 29th URSI General Assembly, B07.3, Chicago, Ill, USA, August 2008.

[19] S. E. Schwarz, "Efficiency of quasi-optical couplers," International Journal of Infrared and Millimeter Waves, vol. 5, no. 12, pp. 1517-1525, 1984.

[20] C. A. Balanis, Antenna Theory: Analysis and Design, Wiley, Hoboken, NJ, USA, 1982.

[21] HSCH-9161 GaAs Detector Diode Data Sheet, Avago technologies.

[22] I. J. Bahl and P. Bhartia, Microwave Solid State Circuit Design, chapter 6, Wiley, Hoboken, NJ, USA, 2nd edition, 2003.

[23] Y. Deguchi, K. Sakakibara, N. Kikuma, and H. Hirayama, "Millimeter-wave microstrip-to-waveguide transition operating over broad frequency bandwidth," in Proceedings of the IEEE MTT-S International Microwave Symposium Digest, IEEE, June 2005.

[24] F. T. Ulaby, R. K. Moore, and A. K. Fung, Microwave Remote Sensing, Artech House, Norwood, Mass, USA, 1981.

[25] K. Iga, K. Kokubun, and M. Oikawa, Fundamentals of Microoptics, Academic Press, New York, NY, USA, 1984. 


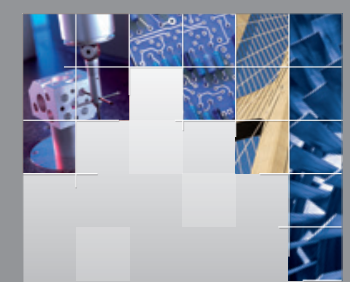

\section{Enfincering}
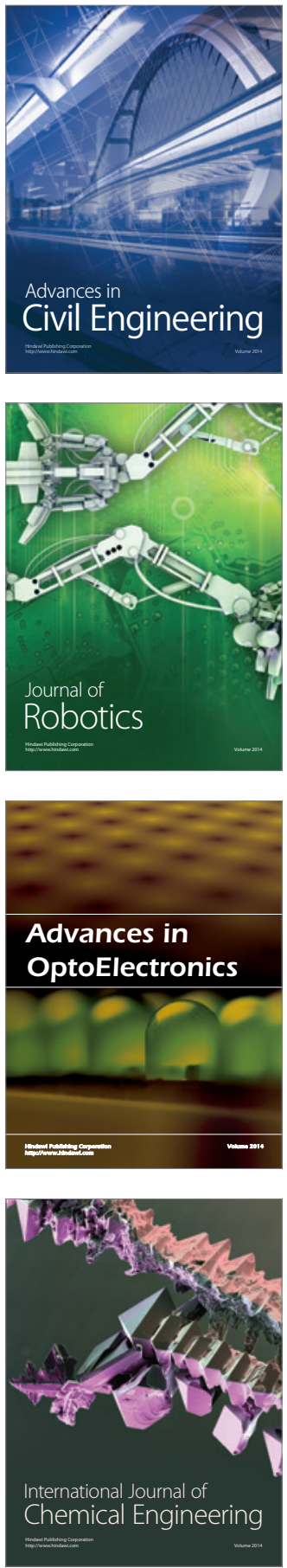

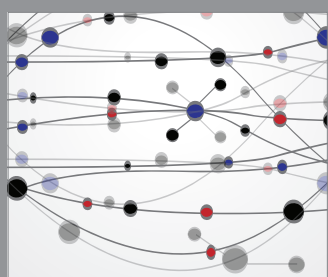

The Scientific World Journal

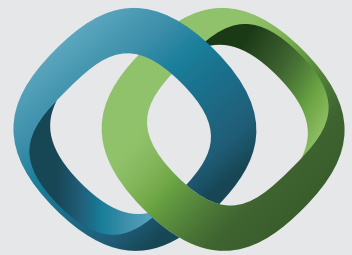

\section{Hindawi}

Submit your manuscripts at

http://www.hindawi.com
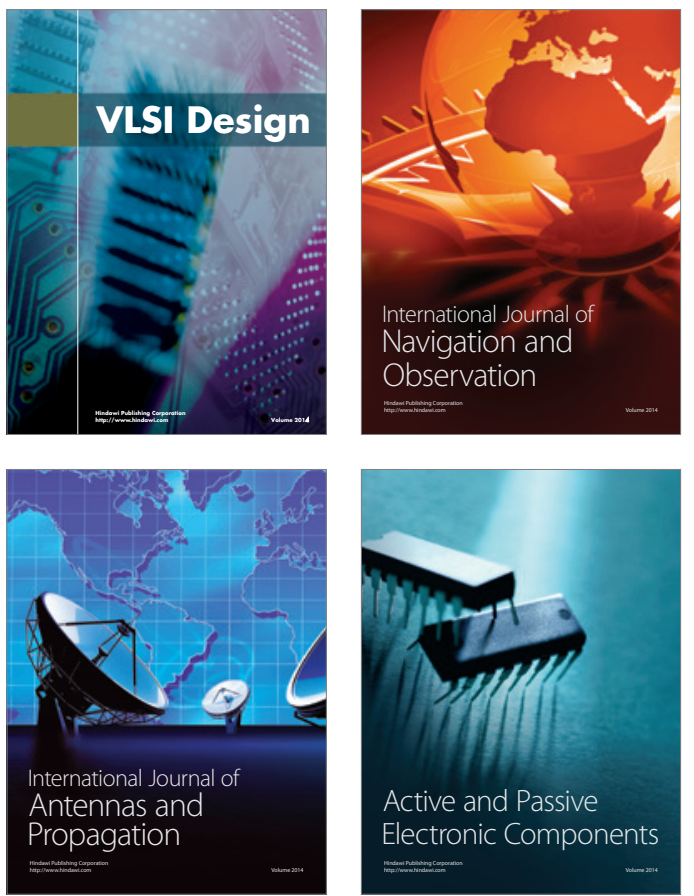
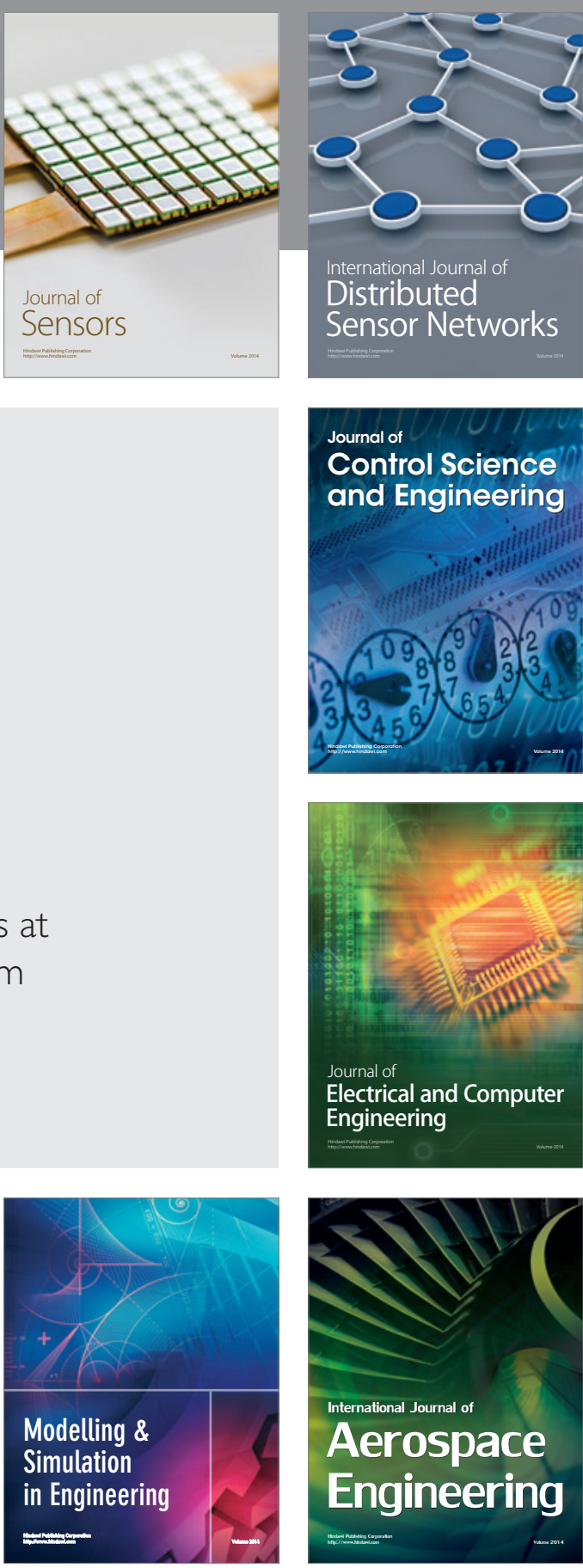

International Journal of

Distributed

Sensor Networks

Journal of

Control Science

and Engineering
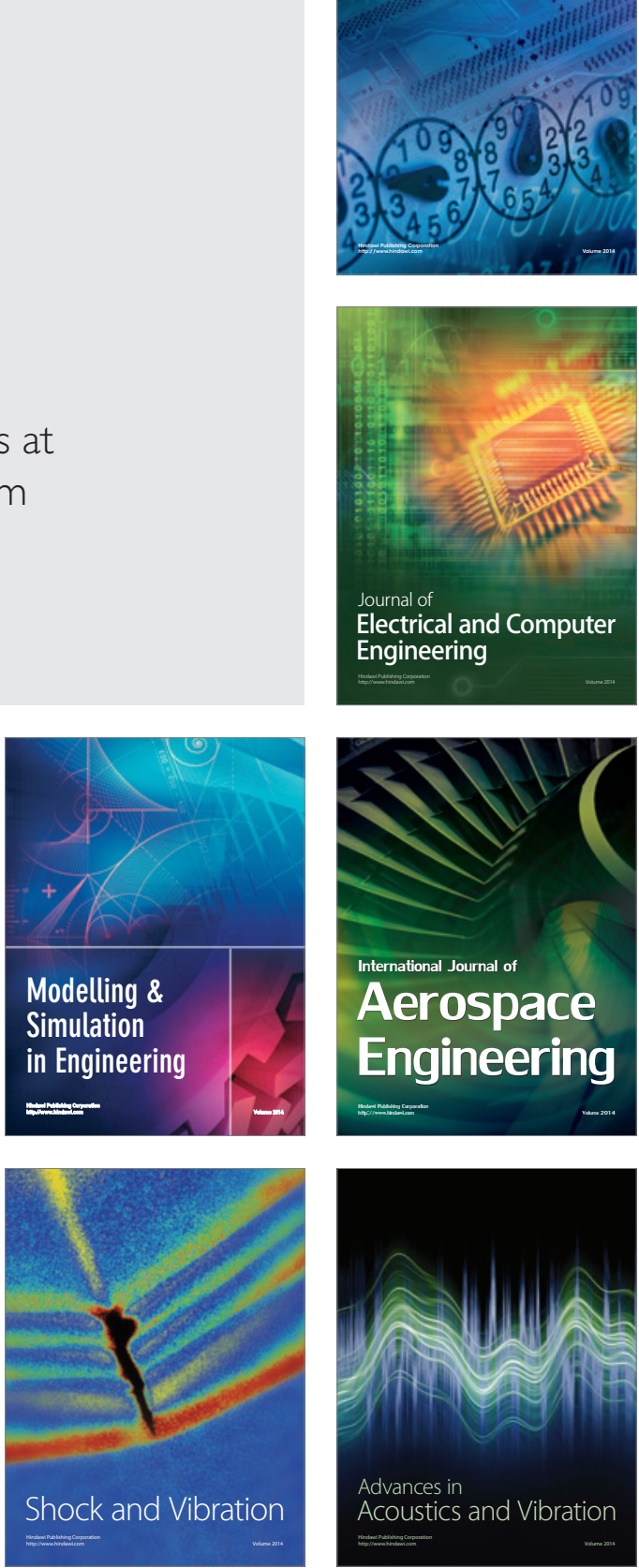